\title{
The Politics of Intranet Usability: Can One Size Fit All?
}

Link to publication record in Manchester Research Explorer

\section{Citation for published version (APA):}

Procter, R., Gallacher, S., Williams, R., Bawa, J. (Ed.), Dorazio, P. (Ed.), \& Trenner, L. (Ed.) (2001). The Politics of Intranet Usability: Can One Size Fit All? In The Usability Business: Making the Web Work (pp. 109-118). Springer Nature.

\section{Published in:}

The Usability Business: Making the Web Work

\section{Citing this paper}

Please note that where the full-text provided on Manchester Research Explorer is the Author Accepted Manuscript or Proof version this may differ from the final Published version. If citing, it is advised that you check and use the publisher's definitive version.

\section{General rights}

Copyright and moral rights for the publications made accessible in the Research Explorer are retained by the authors and/or other copyright owners and it is a condition of accessing publications that users recognise and abide by the legal requirements associated with these rights.

\section{Takedown policy}

If you believe that this document breaches copyright please refer to the University of Manchester's Takedown Procedures [http://man.ac.uk/04Y6Bo] or contact uml.scholarlycommunications@manchester.ac.uk providing relevant details, so we can investigate your claim.

\section{open $\partial_{\text {ACCESS }}$}




\title{
'The Politics of intranet usability: can one size fit all?
}

\author{
Scott Gallacher and Robin Williams \\ Research Centre for Social Sciences \\ University of Edinburgh \\ Rob Procter \\ Institute for Communicating and Collaborative Systems \\ Division of Informatics \\ University of Edinburgh
}

\begin{abstract}
This case study follows the twists and turns in a corporate intranet application project within a large UK bank. It reveals decision-making - from the project's inception through to its development and testing - to be a highly politicised process as various players sought to use the project as a vehicle for pushing forward their own particular agendas. A key consequence of this was that usability issues -- if they were considered at all at this time -- often took second place to the needs of political dealmaking. That these deals were critical to gaining approval for the project seems undeniable, but they also jeopardised the prospects of achieving a usable application, often leaving usability staff to 'pick up the pieces'.
\end{abstract}

The case study illustrates the often highly political character of organisational IT projects, and demonstrates the importance for usability experts of getting involved at the earlier, formative stages of the project lifecycle, when many of the decisions that will map out a project's organisational and technical trajectories are actually made. Though it is unlikely to challenge radically the political character of project decisionmaking processes, it would at least enable usability experts to become players. As other IT professionals have found out before them, to have responsibility without power is an unenviable position in which to find oneself in any organisation (Fincham et al., 1994).

\section{Introduction - 'Do we really need an intranet?'}

Many studies have drawn attention to the threats to usability that frequently emerge in the design and development phases of IT projects (e.g., Poltrock and Grudin, 1994). This case study goes further by illustrating how, despite the rhetoric, usability issues continue to be treated as a side-show in many IT projects. It demonstrates how the capacity of project team members to satisfy usability requirements may be compromised by the often intensely political nature of processes that are instrumental in getting projects approved.

The immediate, tactical aim of the project was to demonstrate the possibilities for delivering interactive, multimedia-based training materials to staff directly through the bank's branch network. The longer term, strategic aim of the project was rather more ambitious, being nothing less than to convince the bank's Executive Board that there was a sound business case for investing in the creation of a single, integrated corporate intranet. This was to have an important influence on the subsequent course of the project. 
BigBank $^{1}$ is a large UK bank that prides itself in having a strong track record in technical innovation. As our case study opens, BigBank's Technology Division had just successfully completed a pilot intranet project. Almost immediately, moves were afoot among certain players within Technology Division and the Bank's Corporate Communications department to get BigBank's board to approve the development of a full scale, corporate intranet. While the pilot project had provided a useful, practical example of the benefits that an intranet could provide, the champions of the corporate intranet project would have to make a separate business case for this new investment. Building a business case for a corporate intranet would not be easy, as one of the project champions explained: "Justification for Intranet systems is usually a soft case and this has to be sold to hard-nosed bankers. The cost-benefits of the system are often long term and difficult to quantify."

What the project champions needed was an application that would justify the investment by demonstrating real financial benefits. Having found it, they could then put together a coalition of political support and technical expertise that could ensure the project's survival and eventual success. In the process, they would have to make compromises over the project's technical specifications and set limits on its scope in order to deliver a usable and useful application.

\section{Getting the go ahead: cost, timing and glamour}

The project champions found what they were looking for in the shape of a new, network-based training tool, the Network Training and Communications System (NTCS), with Corporate Communications as the project sponsor. In early lobbying for the project, its champions presented the following vision:

"Corporate Communications plan to revolutionise the Bank's training and communication strategy through an exciting business vision known as the Network Training and Communications Service (NTCS). In branches, NTCS will be delivered via one or more (depending on the size of the branch) PCs. These PCs will be powerful multimedia machines that run a web browser and have a 'network' connection (yet to be fully defined). NTCS will support Intranet access and interactive training and will provide the hardware, software and network framework for running and managing of (CD-Based) multimedia training and collecting trainee data via the web browser. All these facilities will be accessed and managed via the web browser on the PC."

While this pitch evidently attempted to capitalise on the glamour of multimedia and the WWW, in the event, what made NTCS so attractive to the Bank's IT strategists was its timeliness. The expected imminent arrival of the Euro would soon necessitate widespread training for Bank staff, an extremely costly investment as the Bank must pay not only for the instructors, but also for venues, and foot the transport and accommodation bill for trainees. In addition, the Bank loses the work of that employee for the period of the course. Corporate Communications argued that delivering training over a corporate intranet, using NTCS, would greatly minimise or, in some cases, even eliminate these costs. One of the project champions explained the business case somewhat more prosaically as follows:

\footnotetext{
${ }^{1}$ The names have been anonymised throughout.
} 
"The original benefits [of the earlier pilot intranet project] were the cost of printing the phone book, calls to switchboard, directory enquiries calls. With the combination of training, costs were saved regarding costs of transport and accommodation incurred sending people for training plus the time lost through them being away."

\section{Mobilising Support and Getting Approval}

With the broad business aims established and a project sponsor in place, it was still necessary to carry out a feasibility study of the solution proposed. This would in itself require a budget, but with the desired level of interest achieved this was now easily found. The aim of the study was to cost out the project and investigate technical, usability and logistic issues. Regarding the latter, within an organisation as large as BigBank, it was important that communication was organised and actions coordinated between relevant organisational players. As one of the project champions explained:

"There are three components to any project within the Bank: the business and the Technology Division, which has two sections -- System Development and IT Services. System Development people manage the relationship, getting the requirements and designing the system, while IT Services handle the infrastructure for that technology. In this project there has been a very open dialogue between these sections."

Meetings were arranged with members of these key organisational players and a network created within the Bank that would support the project. A major selling point to them was the opportunity to be involved in a potentially high profile project that would advance their individual positions. By securing this involvement, the project champions sought to circumvent anyone raising problematic issues at a later stage and arguing against the project. This 'buy-in' would be crucial to the project gaining final approval.

The inclusion of usability investigations at this formative stage of the project was a promising sign that usability issues would receive the attention they deserve. However, even here, political considerations held sway. The results of these investigations were used selectively such that those that demonstrated the project in a positive light were put to the fore, whereas those that raised questions, or problematised the project in some way were set to one side. Only lip service was paid to the practical lessons learnt, with guidelines traded off against political needs.

\section{PC or TV? - The Vision is Compromised}

In order to clinch the all-important blessing of the BigBank board to progress from the feasibility study to the project proper, however, the project champions found themselves having to retreat on some of the original plans which left the project having to grapple with significant technical legacy issues.

First, because of the fundamental importance of the content for the application (in this case the training materials), it was important to use a medium that would allow uncomplicated migration from the previous method of delivery to the new one. Trainers up until that point had worked in a classroom environment operating lecture style delivery with slides in Powerpoint format. It was possible to use this medium directly within the new system, but it was not the most effective format. HTML pages were preferred as they allowed a greater degree of flexibility and placed less load on 
the Bank's network. As a result of discussions with the lead trainer, it was decided that opting for the Powerpoint medium would be the most pragmatic option at that point. It was reasoned that because the new system was providing a large 'culture shock' for the present trainers, it was important to ease their entry into the new system as much as possible. The use of the already familiar Powerpoint system would allow this as well as eliminating a need for immediate retraining of the trainers that would add to the forecast cost. This compromise would also, critically, provide the system with immediately suitable material and assure the support of the trainers.

Second, and perhaps most crucially, the project champions had to agree to dilute the intranet delivery concept. Originally, the NTCS project team had planned to use Microsoft's Netshow to create and deliver the audio-video broadcast content over the intranet, which would allow the whole system to be delivered through a single point of access: the desktop PC, as well as allowing for future technical advances. The feasibility study had demonstrated that this would be possible. However, the sizeable prior investment in the Bank's own TV network (BigBankTV) made this financially and politically inexpedient.

To pursue the original plan would "tread on the toes", as one of the project leaders put it, of BigBankTV. BigBankTV used a very expensive, leased satellite link to broadcast to TV sets in each branch from a central studio run by Corporate Affairs. The project had been very costly (in the region of $£ 3$ million) and was widely regarded in the Bank as an "ego trip" on the part of the Board since it was widely seen as providing only a short-term technical solution. Corporate Affairs realised, however, that if they integrated the new system with BigBankTV it would appeal to the Board, by making the new system appear more cost effective, and thereby also strengthening its political support. In the event, it was decided to incorporate BigBankTV into NTCS, using the BigBankTV network to broadcast training classes into the branches. One of the project team explained:

"When we first looked at NTCS, we looked at NetShow Theatre as well as NetMeeting. We came back to the business and said "if you want it in its current state ... then it will probably cost an extra $£ 100,000$ with servers and management etc." The business said "No, we would rather maximise our investment in satellite TV." Undoubtedly at some point in the future we'll look at putting it all on the network as satellite time is so expensive."

As with the decision to use Powerpoint, this created restrictions for NTCS that would compromise its usability. This solution required the incorporation of the TV into the intranet set up, requiring trainees to monitor two displays simultaneously. It allowed little scope for future development. While NTCS was made technically weaker and less usable by this change, the case for it was conversely made much stronger and, in the end, it was this consideration that carried the day.

\section{Political tradeoffs: more expertise means less control}

With the project approved and budgets in place, the next important task for the NTCS project team was to gather the resources to undertake the work. The biggest problem that the team was faced with was gathering the skill base it would need to implement the project. This would require delicate manoeuvring on the part of the project leaders as they sought to balance the political need to harness the support of various in-house 
players against the sometimes superior expertise and experience available through external suppliers.

The Bank's Technology Division wasn't best equipped to provide the multimedia/web technology skills needed for the project, as this was still relatively virgin territory for them. As a project team member was to comment later: "We're gradually skilling up. These skills are in such demand. There's always the temptation to go to third party providers but I feel morally we have to keep as much of the work in-house because if we don't start skilling up our people in these technologies we're going to be ${ }^{* *}$ ked!"

The alternative was to buy in the expertise needed from outside. During the feasibility study stage of the project, interested parties in BT had heard of the planned project. The consultancy wing of BT decided it was a project that they should tender for. Bypassing the usual channels, they approached Corporate Communications directly to arrange a meeting. Corporate Communications agreed, underlining their position of strength by reminding the Technology Division that they weren't the 'only game in town' and would have to tender like everyone else. News of this development created fears within the project inner circle (essentially the feasibility team) that they would find themselves ceding control to BT, and with it much of the share of the credit they hoped would accrue from a successful project. With a heightened sense of urgency, they set about the task of eliminating the threat posed by BT by putting together a rival array of expertise. At the same time, the NTCS team used their inside knowledge of the project to press on with its development in order to make it more time consuming to bring in a third party who would need to retrace the progress made.

Since it would take the Technology Division time to assemble the necessary skills and experience, the only solution would be to recruit an alternative, external party, one that could be controlled more easily than the likes of BT. Having (perhaps unwittingly) motivated the search for an alternative external partner, Corporate Communications now came up with the solution. JNM are a small software house based in the South of England. Their principal product was a presentation system that had the capability to register and poll responses and provide an immediate graphical representation of the results. This system had been widely used at various conferences throughout the UK and they were reputedly the leaders in this field. It was via their conference work that they had come into contact with representatives from Corporate Communications who were taken by the slick graphical representations and interactivity. When they decided to pursue Intranet-based training, they decided that this was a feature well worth incorporating.

A closer examination of JNM's system revealed several shortcomings for the NTCS project, however. Developed for use in an isolated conference scenario, it had very limited capacity in its current form to be re-scaled for use within a large organisation. In the circumstances, however, the project feasibility team agreed that using JNM would prove beneficial for the image of the project and politically, even though acknowledging among themselves that NTCS would be more successfully developed in-house without JNM's involvement. Technical considerations had to be balanced against the political situation and Corporate Communications were keen to involve JNM. The involvement of JNM would undoubtedly provide benefits in selling the project as they could present a system that already existed and which could be 
demonstrated, and this would understandably carry more weight than assurances that a new system could be built.

Two more pieces of the expertise jigsaw remained to be put in place. The importance of content within the NTCS meant that the involvement of the Training Unit was vital. As the project gained approval, the Training Unit was consulted to provide a more direct input into the system. It was also important to allay their fears on the effect that it would have on their jobs. The project leader commented: "At first they were a bit frightened and didn't understand (the system). You're taking people who have spent 20 years of their working lives teaching people in classrooms, then throwing all this technology at them and saying - 'this is how we want you to do it now'."

In order to enlist the full support of the Training Unit, the NTCS team sought to involve them in the decision-making and design process, but also needed to moderate this process. To this end they created close working ties with one of the senior trainers, who acted as the chief point of contact and managed communication between the two sections. The project leader again: "Some of them were a bit scared at first but we had the senior trainer ... She would get suggestions from the other trainers then discuss them with us. Then she would go back, let them know what was feasible and the possibilities and so on. It worked very well."

In another politically motivated decision, trainers were the only end user group consulted at this time. Those who would use the system in the role of trainees were excluded from involvement in determining the system requirements. This was because while the trainers' support was vital to the project's survival, that of end users was not, and the project leadership was fearful that if trainees were involved at this stage, conflicting requirements might emerge and derail the project.

The final expertise required was that of user interface design. The Learning Technologies Department (LTD) had been created as an arm of the Bank's Human Resources department, and specialised in the production of multimedia CDs to be distributed for use by stand-alone clients in the branches. This was an area in which the Technology Division had no capability or skills and so LTD had been allowed to grow autonomously. With the initiation of the NTCS project, however, as multimedia technology moved towards networked systems incorporating web technologies capable of interactive training, it was inevitable that the interests of LTD and the Technology Division would overlap and eventually conflict. In the circumstances, it was not difficult to convince LTD, who had felt very threatened by the project, to take on the job of user interface design. As the project leader explained: "We said - 'look, we're just technologists, we can make it work and you just design the screens. Tell us what you want it to look like, paint the picture and we can do it'. We backed off doing any 'look and feel', we're not experts in that."

The chief technical expert of LTD actually carried out the work. It is only at this point that we find that a usability expert finally gets involved. The project leader noted how: "Jim Smith did the screen design based on what the senior trainer (who was representing a whole bunch of trainers) had advised. Jim has a good eye for usability anyway - that's his key skill." 
Just when it seemed that the project was heading for a successful conclusion, however, the consequences of some of the earlier compromises finally became apparent as the project moved into the testing and role out phases.

\section{Testing and Roll Out: 'Keep it simple' wins the day}

The decision to use BigBankTV required that TVs and PCs be located within the branches in mutually accessible places, and this was eventually to prove a considerable stumbling block. The original placement of the TVs within the Branches had been chosen to allow the whole of the staff to view BigBankTV broadcasts, whereas meeting the needs of an interactive training system required a more isolated setting. The Bank's Property department established that moving the TV with fittings and connections to a location that was compatible with both purposes would be very costly, and even physically impossible in some branches. So, late in the day, the NTCS team returned to the aim of incorporating the TV image within the PC. A number of ways of achieving this were identified:

- TV tuner card to feed the signal into the PC for display on the screen.

- A system for delivering images via networks using new technology that was unproven, but was backed by BT.

- A second system for delivering images via networks using technology that was proven, but from a supplier unknown in the UK.

In the event, both the network-based suggestions were rejected because, in their different ways, they were judged to be too risky at this late stage in the project lifecycle. This left the first option of using the TV tuner card, which was not as forward looking as the other options, but was proven and did not require direct integration with the system.

The project survived this final alarm, and was eventually successfully rolled out into the branches. However, it is clear that this outcome owed little to a systematic, principled and early consideration of usability issues and rather more to the project team's capacity to salvage something from a crisis. Though this particular project was considered a success, we argue that coping with usability threats as they arise is, in general, a risky strategy for usability staff to pursue. Instead, they need to become more politically aware and seek out organisational positions that will enable them to foreground usability issues from the very beginning.

\section{Lessons Learnt}

- Many of the decisions that will map out a project's organisational and technical trajectories are actually made as the key players struggle to get the project approved.

- These decision-making processes are often shaped by the immediate exigencies of organisational (and inter-organisational) politics, with the result that usability issues can easily be subordinated to other concerns.

- The implications for usability of decisions made at these early stages in a project can be hard to undo.

- To counter these problems, usability experts should be prepared to get involved at these formative stages of the project lifecycle. 
- This is unlikely to challenge the political character of project decision-making processes, but it would at least enable usability experts to become players and so acquire some power to match their responsibilities.

\section{References}

[1] Fincham, R., Fleck, J., Procter, R., Scarbrough, H., Tierney, M. and Williams, R. (1994). Expertise and Innovation: IT Strategies in the Financial Services Sector. Oxford University Press.

[2] Poltrock, S. and Grudin, J. (1994). Organisational Obstacles to Interface Design and Development. ACM Transactions on Computer-Human Interaction, vol.

$1(1)$, p. $52-60$. 